\title{
LETTERS
}

\section{Misconception about the cause of vitamin D toxicity}

In the case reported by Auguste and colleagues, ${ }^{1}$ we believe that the patient experienced vitamin $D$ intoxication because of an underlying pathologic condition that the authors failed to recognize.

The authors incorrectly concluded that a dose of 8000-12000 IU daily can result in vitamin $D$ intoxication. Vitamin $D$ toxicity generally occurs when the level of 25-hydroxyvitamin $D$ is greater than $375 \mathrm{nmol} / \mathrm{L}(150 \mathrm{ng} / \mathrm{mL}) .^{2}$ This patient had a 25-hydroxyvitamin D level of $241 \mathrm{nmol} / \mathrm{L}$ (96 ng/mL). This concentration is considered to be within the normal limit (30$100 \mathrm{ng} / \mathrm{mL}$ ) according to the Endocrine Society's clinical practice guideline. ${ }^{3}$ Daily ingestion of $10000 \mathrm{IU}$ of vitamin $\mathrm{D}_{3}$ raising blood levels of 25-hydroxyvitamin D above $100 \mathrm{ng} / \mathrm{mL}$ was not associated with hypercalcemia, as reported in a review. ${ }^{2}$ Population studies have also reported that doses of up to 20000 IU daily were not associated with toxicity. ${ }^{2}$

Levels of 1,25-dihydroxyvitamin $D_{3}$ are not increased in patients with vitamin D intoxication with hypercalcemia, because of the suppression of parathyroid hormone reducing renal conversion of 25-hydroxyvitamin $D$ to 1,25-dihydroxyvitamin D. ${ }^{2,3}$ The high levels of 1,25-dihydroxyvitamin $D_{3}$, and the fact that the authors observed that treatment with hydroxychloroquine resulted in a rapid decline in circulating levels of 1,25-dihydroxyvitamin $D_{3}$, should have alerted the authors that the likely explanation was the unregulated extrarenal conversion of 25-hydroxyvitamin D to 1,25 -dihydroxyvitamin $\mathrm{D}$. The renal 25-hydroxyvitamin D $1 \alpha$-hydroxylase (CYP27B1) is not sensitive to hydroxychloroquine, ketoconazole or glucocorticoids as suggested by the authors. Only the extrarenal CYP27B1 is sensitive to these medications. ${ }^{4}$

The authors made a modest effort with imaging studies to rule out granulomatous disorders. However, they did not appreciate the patient's previous history of urothelial carcinoma, which has been reported to be associated with vitamin D toxicity associated with unregulated extrarenal conversion of 25-hydroxyvitamin $D$ to 1,25-dihydroxyvitamin $\mathrm{D}$. This was the likely cause of the patient's vitamin D intoxication and renal failure, not the dosage of vitamin D. ${ }^{5}$

\section{Nipith Charoenngam MD}

Postdoctoral research fellow, Section of Endocrinology, Diabetes, Nutrition and Weight Management, Department of Medicine, Boston University School of Medicine, Boston, Mass.

\section{Arash Hossein-Nezhad MD PhD}

Research assistant professor, Section of Endocrinology, Diabetes, Nutrition and Weight Management, Department of Medicine, Boston University School of Medicine, Boston, Mass.

\section{David A. Hanley MD}

Professor emeritus, Departments of Medicine, Community Health Sciences, and Oncology, Cumming School of Medicine, The University of Calgary, Calgary, Alta.

\section{Michael F. Holick MD PhD}

Professor, Section of Endocrinology, Diabetes, Nutrition and Weight

Management, Department of Medicine, Boston University School of Medicine, Boston, Mass.

Cite as: CMAJ 2019 July 8;191:E769. doi: 10.1503/cmaj.72511

\section{References}

1. Auguste BL, Avila-Casado C, Bargman JM. Use of vitamin $D$ drops leading to kidney failure in a 54-year-old man. CMAJ 2019;191:E390.

2. Holick MF. Vitamin D is not as toxic as was once thought: a historical and an up-to-date perspective. Mayo Clin Proc 2015;90:561-4.

3. Holick MF, Binkley NC, Bischoff-Ferrari HA, et al. Evaluation, treatment, and prevention of vitamin D deficiency: an Endocrine Society clinical practice guideline. J Clin Endocrinol Metab 2011;96:1911-30.

4. Adams JS, Hewison M. Extrarenal expression of the 25-hydroxyvitamin D-1-hydroxylase. Arch Biochem Biophys 2012;523:95-102.

5. Asao K, McHugh JB, Miller DC, et al. Hypercalcemia in upper urinary tract urothelial carcinoma: a case report and literature review. Case Rep Endocrinol 2013;2013:470890.

Competing interests: Michael Holick is a consultant for Quest Diagnostics Inc. and Ontometrics Inc., and is on the Speaker's Bureau for Abbott Inc. David Hanley has received research funding from the Pure North S'Energy Foundation. No other competing interests were declared. 